\section{METALS AND GASES}

\section{Controlled Atmospheres for the Heat Treatment of Metals}

By Ivor Jenkins. Pp. $x+532+60$ plates. (London : Chapman and Hall, Ltd., 1946.) 50s. net.

COMPLETENESS of the field covered, with
authoritative discussion of both theoretical and
practical aspects of the subject, make Mr. Jenkins'
volume a book which will undoubtedly become a
standard work of reference. It is particularly wel-
come, in that it possesses the additional merit of
being written throughout in a concise and interesting
manner. It is probable that in many cases the
practical worker will not desire to study all the
theoretical background of the technique which he is
employing; but the arrangement of the material is
such that the more practical aspects can be separately
considered. At the same time the theoretical side is
dealt with in a manner which will be of real interest
and value to the more academic reader, and the
author's intention of bridging the gap between the
practical and academic aspects of the subject is
successfully achieved. The use of special atmospheres in the heat treatment of metals has assumed greatly increased importance in recent years, but the information has been scattered, and the wide range of applications dealt with in the present volume will probably surprise many readers. On one hand, there are the various atmospheres used to prevent oxidation, carburization or decarburization of steels during heat treatment, or to avoid oxidation or selective depletion of surface layers with non-ferrous materials. The composition of such atmospheres must often be designed as a compromise, balancing the conflicting tendencies of the various equilibria over the range of treatment conditions, and making the problem much less simple than might appear at first sight. On the other side are those conditions where composition and treatment are deliberately adjusted to obtain carburization or nitriding of steels, and in these cases, factors such as depth of case and concentration gradients may become of first importance.

The complexity of treatment which may be involved is well illustrated from the description of steel carburizing technique. Thus in certain cases the material may first be treated under slightly decarburizing conditions to activate the surface, and then subjected to carburizing treatment, involving the three stages of low-temperature sooting, carburization proper, and diffusion of the carbon to give the desired concentration gradient. Finally, the material must be heated for hardening in an atmosphere such that surface decarburization does not occur. These and the many other successful applications of controlled atmospheres are discussed theoretically and practically in some three hundred pages dealing with industrial applications, while earlier sections of the book deal in detail with the generation, purification and analysis of the various types of atmosphere employed.

While there may occasionally be some difference of opinion as to the precise value or interpretation to be put upon some of the published data quoted in the more theoretical sections, the careful survey of this material which the author has included throughout the book is a most valuable feature. In view of the detailed consideration given to carburizing and nitriding treatments, it would have been interesting to have had some reference to the role of gases in metallic cementation; but otherwise the ground covered is remarkably complete.

The usefulness of a book can be considerably affected by the clarity of its presentation. In the present case, author and publishers are to be congratulated, not only on the general arrangement and typography, but also on the wealth of excellent illustrations, which are a most valuable feature of the book.

C. S.

\section{FOUNDATION OF THE JOHNS HOPKINS HOSPITAL}

The Johns Hopkins Hospital and the Johns Hopkins University School of Medicine

A Chronicle. Vol. 1. Early Years, 1867-1893. By Prof. Alan M. Chesney. Pp. xviii $+318+37$ plates. (Baltimore, Md. : Johns Hopkins Press; London : Oxford University Press, 1943.) 18s. 6d. net.

7 HE reputation of the Johns Hopkins Hospital was founded upon the inspired endeavours of a few great men, and in this volume Prof. A. M. Chesney gives the story which he has unearthed from documents in the archives in the Hospital and in the University. The result is a work which will be very acceptable to all who are interested in the history of medical education. There are many strong ties between the Johns Hopkins and Great Britainprobably the greatest of which was its gift to us of William Osler, who left the Johns Hopkins in 1905 to take the regius chair at Oxford.

The year 1867 marks the foundation of both the University and the Medical School, since in that year Johns Hopkins caused to be introduced into the General Assembly of Maryland bills authorizing the formation of two corporations to found and administer these separate-though closely connected-institutions. His choice of trustees stamped Johns Hopkins as a man of great discrimination, as his scheme had shown him to be a man of wide vision. The University opened its doors in September 1876 with a "Faculty of Philosophy" consisting of six professors and their assistants. Huxley delivered the address at the opening ceremony. Almost straight away, under the direction of its enlightened president, Daniel C. Gilman, the University introduced courses in the basic sciences required by medical students. There were many unavoidable delays in the building of the Hospital, and it did not open its doors for patients until May 1889. The four Iuminaries who had been induced to take up the leading professional posts are portrayed in Sargent's well-known picture-William Osler (medicine), W. S. Halsted (surgery), Howard A. Kelly (gynæcology), and Welliam H. Welch (pathology). The rapidity with which these four men built up a distinguished reputation for the Hospital is well known.

Prof. Chesney's careful work gives much about the lives of these four men, but it will be valued even more for the brief lives of other giants who are less well known in Great Britain-W. S. Thayer, J. M. T. Finney, J. J. Abel, Franklin Mall, W. H. Howell, and many others. As a guide to the difficulties which beset the foundation of a new institution the work will naturally have great value. We look forward to the appearance of the remainder of this history.

E. ASHWORTH UNDERWOOD 